\section{Where science has gone wrong}

SiR-Only the most casual reading of Popper's writings can have misled Theocharis and Psimopoulos (Nature 329, 395 ; 1987) to summarize Popper's epistemology as requiring "the Earth is a flat disk" to be a valid scientific statement in contrast with "the Earth is (approximately) a sphere". Statements concerning singular empirical facts, such as the latter, are the rocks and foundations of Popper's epistemology, but a simple list of true empirical facts does not constitute a scientific theory.

Scientific models, hypotheses or theories try to condense statements relating to subsets of such sets of empirical facts into fewer, logically consistent statements, which have to reproduce by logical deduction at least their generating subset of facts (In the latter case, this set of statements should be considered only a valid model.) The fewer the statements needed in order to formulate a theory and the larger the subset of "explained" facts, the more potent is the theory. As lists of empirical facts are potentially infinitely large, theories phrased as negations are usually the most powerful. ("There are none but spherical celestial bodies" is such a scientific, albeit invalid, theory.)

Popper's demand of falsifiability requires a theory (as opposed to a statement of a singular empirical fact) to have among its logical deductions at least one statement concerning a new, single, empirical fact (for example, "The Earth is a flat disk"), which in principle can be contradicted by a statement about an empirical observation or the result of an experiment. A case in point is the report by Greenough and Harvey (in the issue of Nature in which Theocharis and Psimopoulos appear, p.585) concerning the refutation of the "neutral theory of evolution" by a cleverly designed experiment.

Unless this theory can be modified to incorporate this new finding, it should be considered a falsified (but still scientific) theory. This example also nicely demonstrates Popper's claim that (unless I run my laboratory by throwing dice) every experiment is, at least to some degree, 'infected' by an underlying theory, which the experiment tries to corroborate or, preferentially, to refute. Without the "neutral theory of evolution", the experiment to which I refer would never have been made.

In sharing the author's evaluation of the other "philosophies" discussed by them and their concern about the decline of the public standing of science, I would suggest as the only remedy that scientists adhere much more closely to the principles of Popper's epistemology. The late Sir Peter Medawar, whom the authors quote approvingly, held Popper's epistemology in the highest esteem and in all probability would have agreed with any advice. For publicly calling Popper a "betrayer of the truth" the authors (and Nature?) owe him a public apology.

\section{DFVLR, Institute of Aerospace Medicine, Biophysical Branch,}

Linder Höhe, 5000 Köln 90, FRG

SIR-Theocharis and Psimopoulos state (allegedly paraphrasing Lakatos), that "if observations are theory-laden, this means that observations are simply theories". Rubbish.

If, whenever I combine my visual observations with ballistics theory $A$, the falling cricket ball hits me on the head; but whenever I use ballistics theory $B$, I catch the ball; then I shall not yet consult an optician and will (provisionally) retain theory $B$. Conjectural it remains, but for me at least, it is superior to the apparently refuted theory $A$. And the bruises on my head enable me to distinguish between theories and observations - or, in this example, between the ballistics and the balls.

Thus reasons Popper; thus indeed does science advance by way of an always incomplete search for greater predictive reliability; and thus is scientific method defined.

To lump together Popper and Feyerabend is perverse; they are as unlike as Kant and Hegel. The attack on Feyerabend's anarchic delusions I could accept, and perhaps he has contributed to that value-eroding "relativism" which Allan Bloom has recently and elegantly castigated $^{1}$. But Popper's three great early works $^{2-4}$ - which Theocharis and Psimopoulos do not cite - remain for many the most scholarly and rigorous defence and definition, not only of scientific method, but of democracy. They are products, moreover, of an Austrian emigré who knew too well the potential damage which philosophical folly and selfconfident certainty can wreak on a society, as surely as Lysenko could (with Stalin's backing) blight Soviet science.

131 rue Verbist,

Mark F. Cantley

\section{B-1030 Brussels, Belgium}

1. Bloom, A. The Closing of the American Mind (Simon \& Schuster, New York, 1987)

2. Popper, K.R. The Open Society and its Enemies (Routlege \& Kegan Paul, London, 1945)

3. Popper, K.R. The Poverty of Historicism (Routledge \& Kegan Paul, London, 1957)

4. Popper, K.R. The Logic of Scientific Discovery (Hutchinson, London, 1959).

SIR-Theocharis and Psimopolous have described the damage done to science by irresponsible philosophical scepticism and its popular derivatives. A similar point could be made about the destructive effects on personal and political morality. History shows the murder- ous consequences of the moral equivalents of the epistemological '-isms' that Theocharis and Psimopolous criticize; and of course scientists are as easily seduced by anyone. In science, as Theocharis and Psimopolous suggest, and also in morality, the frivolous sceptic can often be caught in self-contradiction. Philosophical complacency, however, will not do; contrary to what both sceptics and conservatives often seem to believe, philosophical questions do matter.

Surely, though, Theocharis and Psimopolous are unfair to Popper in the example they use to illustrate his falsifiability criterion. The statements "the Earth is (approximately) a sphere" and "the Earth is a flat disc" are, in principle, both falsifiable (if 'approximately' is defined). They differ only in that the second has been amply falsified, while the first has not been, and (it is impossible to avoid begging the question) is never likely to be.

GRAHAM J. KEMP

\section{Department of Human Metabolism}

and Clinical Biochemistry,

Medical School, Beech Hill Rd, Sheffield S10 2RX, UK

SIR-I was a contributor to the BBC's Horizon programme "Science . . Fiction", of which Theocharis and Psimopoulos complain. Their article attacks the recent philosophy of science and, by implication, sociology and history of science as well. It contains many mistakes and non sequiturs.

Quoting Mrs Shirley Williams, the authors blame diminution of research funds on the failure of science to deliver increased wealth. There may be some truth in that. Since the Second World War, the most lavish spending on pure science has been on fundamental physics and astronomy, which have not delivered much commercial value. But it is odd to blame that failure on physicists' and astronomers' poor grasp of scientific method; there has not been a great deal wrong with the physics and the astronomy, so far as I know.

Likewise, can it be that the excessive funds expended on science in the service of the military arise out of the better grasp of epistemology at the Royal Radar Establishment at Malvern than at Jodrell Bank? The argument that the failure of the sciences to win the support they claim is due to scientists' poor understanding of epistemology is plainly silly.

The authors' assertion that scepticism "entails social, political and every other kind of anarchism and disorder" is dangerously naive. Sceptical ideas can be used to justify wholesale change, but also moderation. Thus Karl Popper attacks totalitarianism because there is no possibility of establishing a science of society sufficiently reliable to justify the moral costs of large-scale social engineering. The opposite side of the coin is that pro- 
gressive models of science can be used to justify democratic institutions, or abhorrent political ideas, such as the "scientifically" inspired and executed "final solution" to the "scientific" problems of racial impurity.

Their "third danger", that sceptical approaches stifle progress, may have a grain of truth, and scientists would be illadvised to engage in too much philosophical sophistry at the laboratory bench. Nevertheless, the possibility of good work is not destroyed by reflection upon the complex nature of science. It is a mistake to think that philosophy can contribute directly to scientific methodology. It is an equally grave mistake to think that the naive motivating ideology of science can provide epistemological foundations. Such aspirations died with logical positivism.

The only thing that makes clear good sense in Theocharis and Psimopoulos is the claim that the privileged image of science has been diminished by the philosophical, historical and sociological work of past decades. One hopes this is the case. Grasping for special privilege above and beyond the world we make for ourselves - the new fundamentalism that Theocharis and Psimopoulos press upon us indicates bankruptcy of spirit luckily not yet widespread in the scientific community.

HARRY COLlins

Science Studies Centre,

University of Bath,

Claverton Down, Bath BA2 7AY, UK

\section{AIDS: Incubation or latency?}

SIR-It is commonly assumed that the clinical manifestations of AIDS (acquired immune deficiency syndrome) follow an 'incubation period' which may be as short as months or as long as many years. 'Incubation' indicates a continuous process that, starting with its determinant cause, will produce its full effect at a relatively fixed time in the future, like the incubation of an egg or of some infectious diseases. To speak of incubation, one must be reasonably certain that the process has a continuity in time that irrevocably links the effect to its cause. When the final effect requires, besides the initial cause, some further condition that may or may not arise in the future, we speak of 'latency'. The manifestation of a disease later in life following the presence of an inherited predisposing characteristic is typical of this case. The exact course of the development of AIDS following contact with the virus is not yet known, but the long and highly variable time between infection and symptomatic course clearly indicates that this is a case of latency rather than incubation.
The distinction of latency from incubation is not simply pedantic. The prolonged absence of symptoms in a large majority of those that have had contact with the virus is already indicative that in many probably most - of them the disease will never develop. The determination of the causes that end the latency of AIDS and bring about its symptomatic course can only be accomplished by a continuing investigation of the cases in which the disease is latent.

It therefore requires the full cooperation of those who are immunologically positive but have no clinical manifestations. Although the public health authorities of many countries, the United States first and foremost, have employed every means to inform the public of the seriousness of the disease, they have done nothing to convince it of the interest and importance of the participation in the research and prevention of the disease of those who are immunologically positive but have no manifest symptoms. In fact, the prejudices of the public against those it sees as potential carriers of the disease have been allowed to reach a point where a person who knows himself to be immunologically positive and has no other symptoms of AIDS would be well advised to hide the fact.

Proper information of the public, and most important the need to regain the confidence of those who have had contact with the virus but show no clinical symptoms, require that the implications of the AIDS infection be honestly presented. A suitable beginning would be the acknowledgement that infection is followed by an indetermined period of latency and that in most cases this may well turn out to be as long as the natural life of the individual.

Department of Biochemistry,

GREGORIO WEBER

University of Illinois,

Urbana, Illinois 61801, USA

\section{Leprosy vaccine}

SIR-I wish to comment on your news article on a new vaccine trial against leprosy being undertaken in Maharashtra, India ${ }^{\prime}$. Recognizing that $a$ third of all patients with leprosy are in the Indian subcontinent, the government of India has made a major commitment to the control of this disease. The UNDP/World Bank/ WHO Special Programme for Research and Training in Tropical Diseases has, through its immunology of leprosy (IMMLEP) programme, supported a number of research efforts to develop candidate vaccines against leprosy. A mixture of killed Mycobacterium leprae together with live BCG vaccine has been shown to be effective in preventing infection in animals. It is currently being tested in controlled trials in 29,000 contacts of leprosy patients in Venezuela and in a general population of 120,000 in the northern region of Malawi.

I wish, however, to correct two misstatements in your article, concerning the possibility that this vaccine may contain retroviruses and foreign DNA. In the light of the stringent procedures for purifying the bacilli from armadillo tissue, including their exposure to DNAase and extensive washing, followed by gamma radiation $(2.5 \mathrm{Mrad})$ and autoclaving ${ }^{2.3}$, the statement that this vaccine contains retroviruses and foreign DNA is entirely incorrect and unfounded.

WHO IMMLEP M. Leprae Bank,

R.J.W. REES

National Institute for Medical Research,

London NW7, UK

1. Jayaraman, K.S. Nature 328, 660 (1987)

2. WHO Report of the fifth meeting of the Scientific Working Group on the Immunology of leprosy. Protocol $1 /$ 79. TDR/SWG/IMMLEP (5) 80.3 (1980)

3. Rees, R.J.W. Int. I. Leprosy 51, 515-518 (1983)

\section{Genome mapping}

SIR-It is more in sorrow than in anger that I protest at the headline of your news story about our genetic linkage map ("Critics denounce first genome map as premature", Nature 329, 571; 1987). The headline seems strangely disconnected from the facts even as they are detailed in your account.

After correctly noting that we will make our probes freely available for research purposes, you report, "[Collaborative] is, however, applying for patents on the probes and stands to gain if (there are) . commercial applications".

Let me assure you that this entrepreneur fervently hopes we stand to gain. That is precisely why we invested $\$ 12$ million in this enterprise. Nature goes on to talk of "cries of commercialism", of anonymous stock analysts who criticize us for an approach to genome mapping "too grand and expensive" and of unnamed critics who accuse us of "scientific merchandising" for reporting our accomplishments.

We confess that we do want to make a buck, honestly. We think investing our shareholders' money in genetic linkage mapping is a good idea for science, and a good idea for our business. I think too much is being made of the gaps and not enough of the map.

If Collaborative Research makes money doing all this, colour us happy and colour those stock analysts green.

OrRIE M. Friedman

Collaborative Research Incorporated,

Two Oak Park,

Bedford,

Massachusetts 01730, USA

Letters submitted for Correspondence should be typed, double-spaced, on one side of the paper only 